\title{
Malvinas, la guerra que nunca acaba
}

\author{
Soldado Argentino sólo conocido por Dios | Fernández Engler | 2017 \\ Cristian Di Renzo*
}

Universidad Nacional de Mar del Plata, Argentina

Recibido: 4 de agosto 2018; aceptado: 23 de octubre 2018

\begin{abstract}
Resumen
En pocas ocasiones se ha visto a la Plaza de Mayo colmada de almas en un clima que desborda algarabía. Paradójicamente, en dos oportunidades, esa expresión de espontaneidad, motivada por un nacionalismo banal presente en la sociedad argentina, se produjo durante la última dictadura civil-militar (1978 y 1982). Particularmente, el 2 de abril de 1982 y con un régimen dictatorial acorralado por diferentes frentes, la sociedad se apresuraba a salir de sus casas para acercarse a ese punto de referencia histórico con el fin de brindar su apoyo a la recuperación de las Islas Malvinas. Sin embargo, tal romance no perduró tras aquel fatídico 15 de junio, al menos con aquellos que fueron al frente y pudieron regresar para intentar reinsertarse en la comunidad. ${ }^{-1}$ En este caso se trabajará con el film Soldado argentino sólo conocido por Dios, dirigida por Rodrigo Fernández Engler y estrenada en el año 2017. En este largometraje, co-producido por Cita con la Vida Emprendimientos Audiovisuales, Midú-Junco Producciones y Fundación Criteria, con el apoyo del INCAA y de las Fuerzas Armadas Argentinas, se expone la historia de tres jóvenes argentinos que transcurre antes, durante y después de la Guerra de Malvinas, pero que pone al descubierto una serie de elementos que permiten pensar a la sociedad como un sujeto activo en el devenir de los acontecimientos.
\end{abstract}

Palabras Clave: Nacionalismo | Sociedad | Incertidumbre | Guerra

Malvinas, the war that never ends

\begin{abstract}
On a few occasions it has been seen in the Plaza de Mayo filled with souls in a climate that overflows with hullabaloo. Paradoxically, on two occasions, that expression of spontaneity motivated by a banal nationalism present in Argentine society, by the last civil-military dictatorship (1978 and 1982). Particularly, on April 2, 1982 and with a dictatorial regime cornered by different fronts, society rushed to get out of their homes to approach that historical point of reference in order to support the recovery of the Malvinas Islands. However, such a romance did not last until after the fateful June 15, at least when he went to the front and returned to try to reinsert himself into the community. In this case we will work with the film Argentine soldier only known by God, directed by Rodrigo Fernández Engler and released in the year 2017. In this film, co-produced by Cita con la Vida. Audiovisual Undertakings, Midú-Junco Producciones and Fundación Criteria, with the support of INCAA and the Argentine Armed Forces, exposes the story of three young Argentines who spend before, during and after the Falklands War, but that exposes a series of elements that allow us to think of society as an active subject in the future of events.
\end{abstract}

Key Words: Nationalism | Society | Uncertainty | War

\section{Contexto histórico}

En estos momentos miles de ciudadanos, hombres y mujeres en todo el pais, en todos los pueblos, en las pequeñas granjas, en las cindades y en esta Plaza de Mayo histórica que ha marcado rumbos a través de la historia nacional, ustedes, los argentinos están expresando públicamente el sentimiento y la emoción retenida durante 150 años a través de un despojo que boy hemos lavado.

(Aplausos y vítores: ¡Argentina! ¡Argentina! ¡Argentina!). ${ }^{1}$

La escena de la Plaza de Mayo desbordando de personas auto convocadas de aquel 2 de abril de 1982, para mostrar apoyo a una causa nacional, es difícilmente equiparable en la historia argentina. La multitud que se movilizó hacia aquel punto de referencia histórico, en señal de apoyo, parecía opacar a la movilización de protesta ocurrida tan sólo unos días antes, el 30 de marzo, convocada por la CGT Brasil. ${ }^{2}$

No es nuestra intención aquí analizar en profundidad el por qué Malvinas es la causa más grande de la nación argentina, ya que los estudios al respecto son abundantes, aunque nunca suficientes, para explicar el sentimiento y las emociones que despierta en la sociedad. ${ }^{3}$ Tan sólo debemos aclarar que el reclamo por la soberanía de las Islas

cristiandirenzo1@gmail.com 
Malvinas, posee múltiples sustentos teóricos, políticos e históricos que la educación se ha encargado de enseñar en las escuelas con el paso de los años, fortaleciéndose durante la última dictadura civil-militar. ${ }^{4} \mathrm{Al}$ respecto, coincidimos con aquellos teóricos que señalan que el nacionalismo (banal) manifiesta expresiones y se reproduce, a su vez, en lo cotidiano otorgando sentido a la "identidad nacional". 5

Tampoco nos podemos detener en profundidad en el análisis del contexto histórico en el cual se produce la recuperación, la guerra y rendición en Malvinas, sino que señalaremos aquellos elementos que contribuyen a una mejor interpretación del film Soldado argentino sólo conocido por Dios.

El 2 de abril de 1982, mediante la "Operación Rosario", las Fuerzas Armadas Argentinas proceden a la recuperación de las Islas Malvinas sin generar bajas dentro de la población civil y militar del archipiélago. ${ }^{6}$ Ahora bien, ¿̇cuáles fueron los factores que confluyeron para que se lleven a cabo tales acciones? En principio, y a los fines de este análisis, podemos sostener que la sociedad argentina, en 1982, era un terreno fértil para la decisión de ocupar las islas.? Pues, por un lado, la causa Malvinas se encontraba presente en la misma y por otro, existía desde 1975 (o aun antes) un clima de violencia y crisis sucesivas que signaron el devenir histórico de la nación. Particularmente, el gobierno civil-militar, autodenominado Proceso de Reorganización Nacional, había profundizado durante los primeros años al frente del país el Terrorismo de Estado, fenómeno que fue acompañado por otros, tales como la aplicación de medidas económicas de corte neoliberal que modificaron la estructura industrial y financiera, dejando marcas que el tiempo aún no ha podido borrar. ${ }^{8}$ Por otra parte, las tensiones existentes inter e intra-armas dentro de las sucesivas cúpulas militares que gobernaron de facto entre 1976 y 1983, en ocasiones dificultaban el proceso de toma de decisiones y la Guerra de Malvinas será un ejemplo de ello. ${ }^{9}$ Temporalmente, nos encontramos frente a la última etapa de la dictadura, en su fase de agotamiento y la derrota en Malvinas significaría su descomposición. ${ }^{10}$

Es en este contexto, entonces, en el que el film que cuenta la historia de tres jóvenes, Juan Soria, Ramón Molina y su hermana Ana, tiene desarrollo previamente, durante y en la posguerra de Malvinas. Si bien podríamos realizar un análisis en particular de cada uno de los personajes, a los fines de este trabajo, nos centraremos principalmente en la figura del joven cordobés Juan Soria por el desprendimiento de consideraciones generales que podemos obtener a través de su relato que oscila entre las incertidumbres y las certezas a lo largo de todo el film. ${ }^{11}$ Por fines organizativos, dividiremos el film en dos grandes bloques titulados: Durante la Guerra de Malvinas y Tras la Guerra de Malvinas, para posteriormente, abocarnos a algunas consideraciones finales.

\section{Durante La Guerra de Malvinas}

El film comienza con un diálogo entre un cabo y un colimba, el "gallego", (que tendrá cierta importancia secundaria en el film), en donde aparece la primer incertidumbre: ¿hacia dónde están yendo ${ }^{12}$ En ese momento, en el barco que los está trasladando, se produce un cruce de miradas entre Juan Soria y Ramón Molina, un amigo de su pueblo que eligió la carrera de militar tras terminar el Servicio Militar Obligatorio y del cual está distanciado a causa del noviazgo de nuestro protagonista con Ana, la hermana de Ramón. Pero a diferencia de su amigo, a Juan la noticia de que debe prestar servicio en las Fuerzas Armadas le causa rechazo, llegando a sostener: Antes que eso prefiero la muerte. Sin embargo, en el momento en el que se le comunica que estaban por desembarcar en las Islas Malvinas, dando fin a la incertidumbre inicial, Juan queda perplejo, atónito de lo que le esperaba al tocar tierra. Esto se confirma ante el primer ataque aéreo británico, el 1 de mayo, cuando su amigo Ramón se percata de la parálisis sufrida por nuestro protagonista y corre en su auxilio. En un clima de hostilidad e incertidumbre, su amigo de toda la vida es quien lo ayuda. Esta situación parece haber limado las asperezas que tenían por aquel noviazgo, hecho que se confirma cuando a Ramón lo destinan a Puerto Argentino, en donde le entrega a Juan una carta para su hermana y le dice: Perdoname, ¡Cuidate! Esta es tal vez la escena más emotiva del film, y le genera a Juan la incertidumbre de no saber hacia dónde estaban enviando a su amigo, un interrogante que lo acompañará hasta el final de la historia.

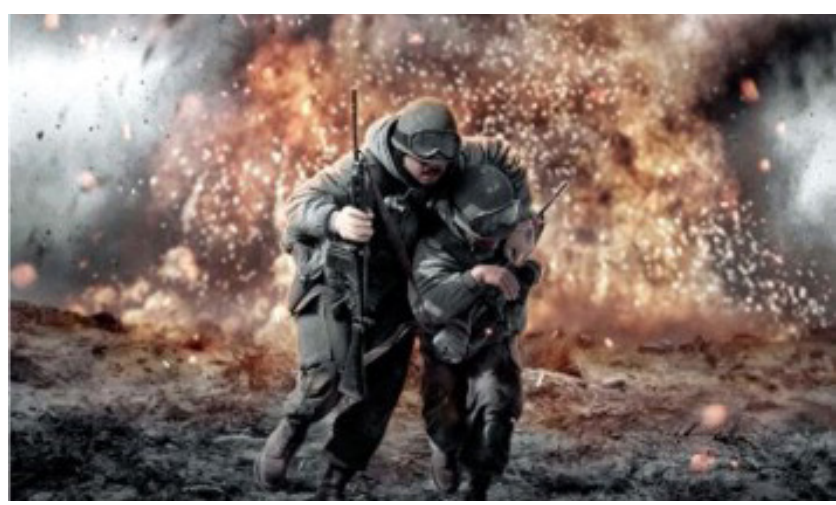


Las aves volando en la naturaleza son las únicas en sentirse cómodas en ese ambiente tan hostil, que encuentra a nuestro joven conscripto cordobés en su primer combate contra los británicos. En ese momento las incertidumbres se convierten en certezas, la guerra había comenzado para ellos y el resultado no sería feliz. Aun así, Juan cumple con las órdenes del subteniente Quiroga y abre fuego (misma situación se produce en el segundo combate, en momentos posteriores). Por lo que manifiesta nuestro protagonista a lo largo del film, su comportamiento, visto desde afuera, sería inaceptable, pues cumplir órdenes de personas que piensan distinto a él y llegar a la situación de matar a otra persona, no estaba en sus planes, empero, la situación en la que se encontraba no le permitía elegir entre demasiadas opciones. ${ }^{13}$

Por otra parte, esa geografía que alberga a tan bella y austera naturaleza se convierte en uno de los enemigos de nuestro protagonista tras el repliegue. En ese largo camino emprendido, el soldado conscripto "gallego", comienza a sentir los avatares del clima y el cansancio. El subteniente Quiroga, ordena a uno de sus hombres a acompañarlo para que lo encuentren los británicos y rendirse. Soria quiere quedarse, pero el subteniente no lo deja, pues sabe que es buen tirador. La guerra se había terminado para ellos. Juan los mira al retirarse ansiando ser él quien se quedara.

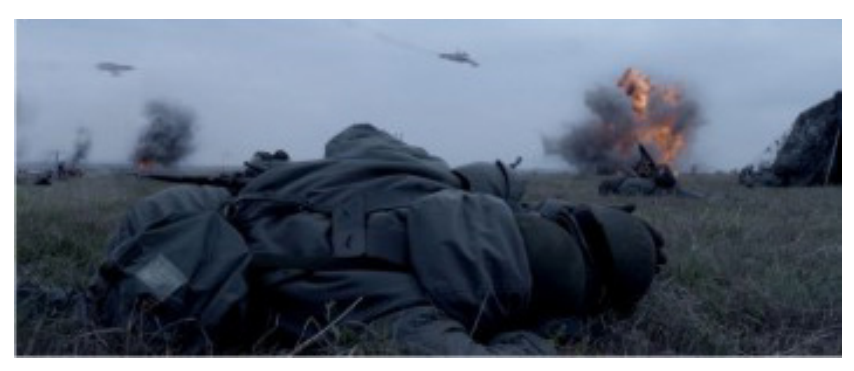

Tras una larga retirada, que tenía como destino Puerto Argentino, son apresados y enviados a un galpón en donde, se encuentran con otros soldados argentinos capturados. El silencio reina entre ellos, corre por debajo una sensación de derrotismo de aquellos que lo perdieron todo. En esta escena, resulta interesante señalar que Juan y sus compañeros encubren al subteniente Quiroga, quitándole el distintivo militar para impedir que se lo lleven a interrogatorio, ya que estaban buscando a oficiales responsables de bajas inglesas. En este sentido, evidenciamos una clara diferencia con el film Iluminados por el Fuego, en donde a lo largo del mismo, se pone de manifiesto que los enemigos no son, necesariamente los ingleses, pues la única escena de combate es confu- sa, con escasa iluminación, sino que los principales actos de violencia y abuso de poder se dan entre los más altos mandos militares y los soldados conscriptos. En Soldado Argentino sólo conocido por Dios, en cambio, el enemigo no son los superiores, sino los británicos o, más bien, la misma guerra, al menos durante el enfrentamiento armado. ¿Vos estabas con Ramón Molina? ¿Qué pasó, donde esta? No, no está, se quedó allá. Se murió, le contesta otro joven. Esto era lo único que no quería escuchar Juan. En ese momento el mundo se le viene abajo, queda perplejo, atónito, desarraigado de su amigo de toda la vida. La guerra, su principal enemigo, se lo había llevado. No sabía que, tras su regreso, tendría otro combate, en donde el enemigo sería la misma sociedad.

Concluye así, la primera parte del film. Las incertidumbres de Juan quedan respondidas, pero también subyace en él un vacío que difícilmente pueda volver a llenar. La frase Hay en mi alma un olvido que vino conmigo $y$ ya no se va. Pero hay en mi alma un amigo que murió conmigo a orillas del mar, perteneciente a la canción oficial del film (autor: Alejandro Lerner), expone el sentimiento que acompañará a nuestro protagonista desde las islas hasta el final de sus días.

\section{Tras la Guerra de Malvinas}

La segunda parte del film, a nuestro criterio, muestra a Ana en una Entrevista con alguien del Comité de Descolonización al que le pregunta sobre un soldado argentino enterrado en el cementerio Darwin, un tal "Soldado Pedro", que ella cree que es su hermano. ${ }^{14}$ Pues Ramón, no sólo había muerto en Malvinas (perdiendo nuestro bien más preciado, la vida), sino que también había perdido su identidad. ${ }^{15}$

Más tarde, Ana acude al encuentro con Juan (que vive solo y alejado de su pueblo y de sus seres queridos), y le cuenta el motivo de su visita, a lo que nuestro protagonista le responde: Yo no tengo más nada que ver con la guerra, asi que no te puedo ayudar. Ante tal respuesta, ella se va, pero él la sigue y le pide que se quede, casi implorándole. Al volver a entrar Ana nota algo que a primera vista no hizo: hay dibujos, obras y representaciones artísticas realizadas por aquel joven que tenía la aspiración de estudiar Bellas Artes, todos ubicados en la pared. El motivo de todas ellas era la Guerra de Malvinas, sus actores y sus emociones. Pues, la guerra seguía acompañándolo. Pues la guerra sí tenía todo que ver con él y así será por el resto de su vida. ${ }^{16}$ 


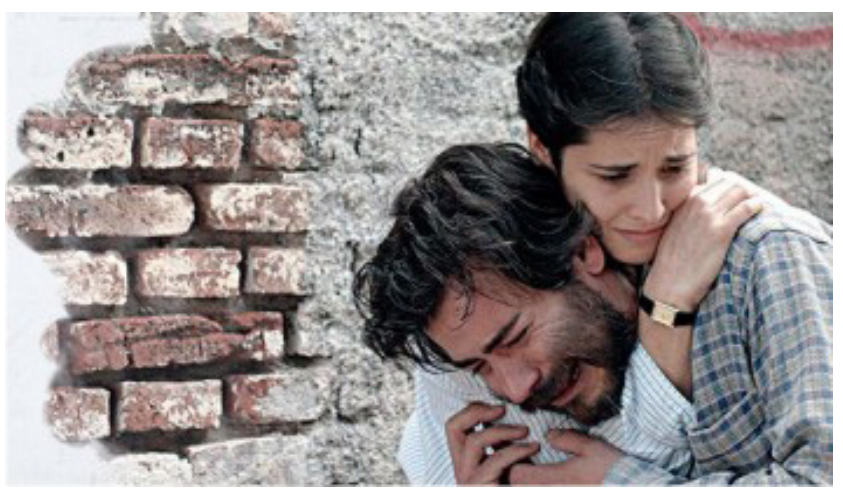

El Veterano con quien tiene que encontrase Ana, en su búsqueda de la reafirmación de la identidad de su hermano, no es otro que el gallego. Al ver a nuestro protagonista, le cuenta que otro colimba de su grupo se había suicidado: Se quedó sin trabajo, se separó de la mujer, nunca fue a las reuniones. ${ }^{17}$ Aquí se devela el nuevo enemigo de aquellos que sobrevivieron a la guerra: la sociedad. Aquella que pobló la Plaza de Mayo el 2 de abril y que no había ido a esperarlos. Aquella que no les daba un lugar. Aquella que prefería que la guerra (tras la derrota) no hubiera existido, como tampoco sus actores. Juan sale, conmovido, hablar de la guerra no le hace bien, se siente superado y rompe en llanto desconsolador. Se mudó solo, no se junta y no va a las reuniones por tal motivo, lo interpela en lo más profundo de su ser. ${ }^{18}$

Al otro día, Ana tiene un cruce de palabras con Antonio (dueño de la pensión en la que "vive" Juan, personificado por Hugo Arana). Él le cuenta que su ex novio se anotó en Bellas Artes, que tiene talento, pero no pasó del segundo año, pues no le es fácil encajar. Además, le cuesta mucho mantener los trabajos, como es clase ' 63 , le preguntan si estuvo en Malvinas. Y no miente. Siempre dice que sí. Entonces en ese mismo momento lo echan o al poco tiempo le inventan una excusa para sacárselo de encima. Así es. Es imposible contradecir aquellas palabras. La voz de la sabiduría del personaje de Antonio se condice con la realidad vivida por aquellos jóvenes que sin saber hacia dónde estaban yendo, se encontraron con la cruda realidad de que al volver, no encontraban un lugar en el cual sentirse cómodos y con la incertidumbre de lo que pasaría con ellos. Pues, para la sociedad, los excombatientes, tras aquel 15 de junio, no formaban parte de la nación argentina, entendiendo a ésta como una comunidad políticamente imaginada, limitada y soberana. ${ }^{19}$ Las miradas esquivas de nuestro protagonista son testigo de ello y el diálogo que mantiene con el gallego, tras el encuentro que tuvieron (junto con Ana) con el ahora capitán Quiroga, entrega lo siguiente:

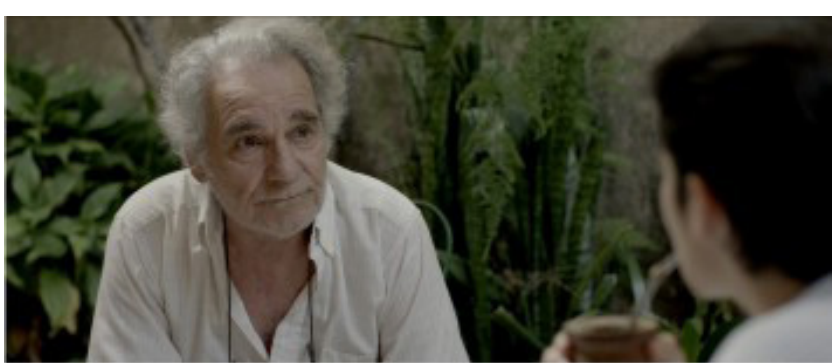

(Gallego indaga porqué Juan no se integra y éste le responde) No se puede, la gente no te deja, gallego, nosotros somos una lacra. Somos los pobres pibes que mandaron a la guerra y que quedamos todos loquitos. Si abora nos meten en la misma bolsa que la dictadura ¿qué tengo que ver yo con eso? Son todos unos hipócritas. Si fueron a la Plaza el 30 de marzo a pedirle a Galtieri que se vaya y fueron después, el 2 de abril, a festejar el recupero de las islas. ¿¿Se puede explicar eso?, a ver, explícame. Decime. ¿se puede explicar? Nos mataron Gallego, nos mataron.

Su compañero no tiene respuesta ante tan lúcido relato de la realidad, pues la misma sociedad no tiene respuestas ante esa situación. Su nacionalismo efervescente, que aparece en escena también ante las victorias en eventos deportivos, dura tanto como tan largo sea el festejo, y luego desaparece, queda como algo cotidiano, pero a la vez irrelevante, reproduciéndose en los lugares más comunes.

El film concluye con una carta que le envían a Ana, en la cual el jefe de la sección en la que se encontraba Ramón, le deja entreabierta la posibilidad de que el "Soldado Pedro" podría llegar a ser su hermano; aquel que al desobedecer la orden del repliegue, ante la superioridad británica, desaparece tras el humo que deja la explosión de una bomba que no reconoce a quien está matando, pues, no es Ramón o el hermano de Ana, ni siquiera el amigo de Juan, sino que es una víctima de guerra.

\section{Conclusiones}

En estas instancias, resultaría una obviedad sostener que la Guerra de Malvinas marcó la relación que nuestros tres personajes tenían entre sí. Pero así fue, y este hecho es ineludible. No obstante, debemos aclarar que fue Ramón el personaje que más sufrió el conflicto, pues si bien se encontraba convencido de la labor que estaba realizando, defender a la Patria, además de perder la vida (nuestro bien más preciado), perdió su identidad.

Por otra parte, en el caso de Ana, ella perdió a Ramón, literalmente, y tras aquel 15 de junio de 1982, lucha por su reconocimiento, no como el héroe que nunca se 
rindió (así cuenta la leyenda del "Soldado Pedro"), sino como persona, como hermano, como hijo y como amigo. Al momento de la redacción de este trabajo, aún quedan 33 excombatientes que no han recobrado su identidad en el Cementerio Darwin de las Islas Malvinas.

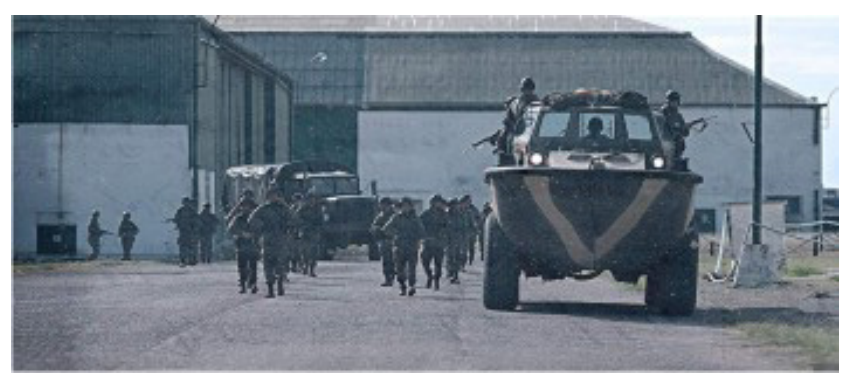

Finalmente, Juan, tras dejar su fusil, entra en un combate diario frente a la indiferencia del Estado y contra los ojos de una sociedad que en un primer momento llenó la Plaza de Mayo, al igual que unos días antes, pero aquella vez (el 2 de abril de 1982) fervorizados por un nacionalismo pocas antes veces visto y nunca repetido en la posteridad.

El 10 de diciembre de 1983, Día Internacional de los Derechos Humanos, se reinstaura en Argentina la democracia. Al mismo tiempo, muchas voces acalladas durante el Proceso, encontraron por primera vez eco público en la sociedad. Sin embargo, no fue así en todos los casos. Pues la lucha por el reconocimiento de los Veteranos de la Guerra de Malvinas continuará por muchos años más, incluso, hasta nuestros días. ${ }^{20}$ En este sentido, el film pone de manifiesto la batalla diaria que tuvieron que enfrentar tras el regreso a sus casas de aquellos jóvenes que estuvieron defendiendo a su patria y que poco tuvieron que ver con la toma de decisiones en la guerra, pues se trataba de los escalones más bajos en la cadena de mandos. Por otra parte, consideramos que el director no ha intentado plagar la obra de aquellas consideraciones que siguen afirmando que a las Malvinas se envió a los "chicos", mostrando como víctimas a los soldados conscriptos por los avatares del enfrentamiento armado. Más bien, intenta mostrar a los jóvenes combatiendo con valentía en las islas contra las dificultades de una geografía hostil, con comunicaciones defectuosas y con una falta de previsión que el Informe Rattenbach se encargó de demostrar. Pero también muestra a jóvenes con interés de reinsertarse en la sociedad, que al marginarlos, los condena y a veces los confunde con todo lo que implicó la dictadura civil-militar que tomó la decisión de recuperar las Islas Malvinas. Pues, para la sociedad, los ex combatientes y en particular, los soldados conscriptos que estuvieron involucrados, no pertenecerían a la nación argentina entendiendo a ésta como una comunidad imaginada.

Así, y tras haber ido a una guerra plagada de incertidumbres, Juan debió (o debe) cargar con el paradójico estigma de haber defendido a su Patria, aquella que sus vecinos y amigos adoptaron en la escuela y juraban año tras año defenderla hasta morir, pero que sólo algunos estaban dispuestos a hacerlo.

\section{Referencias}

Anderson, Benedict (1993) Comunidades Imaginadas: Reflexiones sobre el origen y la difusión del nacionalismo. Fondo de Cultura Económica. México.

Águila, Gabriela (2008) Dictadura, represión y sociedad en Rosario. Un estudio sobre la represión las actitudes y comportamientos sociales en dictadura. Prometeo. Buenos Aires.

Aspiazu, Daniel; Kosacoff, Bernardo (1989), La industria argentina: desarrollo y cambios estructurales CEPAL-CEAL. Buenos Aires

Billig, Michael (2014) Nacionalismo Banal. Capitán Swing. Madrid.

Bonnet, Alberto (2014) La izquierda argentina y la guerra de las Malvinas. Razón y Revolución, no 3. Disponible en http://www. revistaryr.org.ar/index.php/RyR/article/view/456. Consultado en línea el 29/07/2018.

Bourke, Joanna (1999) Sed de sangre. Historia intima del combate cuerpo a cuerpo en las guerras del siglo XX. Critica. Barcelona. Canelo, Paula (2008). El Proceso en su laberinto: la interna militar de Videla a Bignone. Prometeo Libros Editorial. Buenos Aires. - (2012) “Los efectos del poder tripartito. La balcanización del gabinete nacional durante la última dictadura militar”. Revista Probistoria, núm. 17, año XV.

Canitrot, Adolfo (1979) "La disciplina como objetivo de la política económica. Un ensayo sobre el programa económico del gobierno argentino desde 1976" Estudios CEDES, Vol. 2, No 6, Buenos Aires.

- (1982) “Teoría y práctica del liberalismo; política antiinflacionaria y apertura económica en la Argentina, 1976/1981”, en Desarrollo Económico, vol. 21, № 82, Buenos Aires. 
Cardoso, Oscar Raúl; Kirschbaum, Ricardo y van der Kooy, Eduardo (1997) Malvinas: la trama secreta. Planeta. Buenos Aires. Crenzel, Emilio (2008) La bistoria política del Nunca Más. La memoria de las desapariciones en la Argentina. Siglo XXI. Buenos Aires.

Díaz, Claudio. (2010). El movimiento obrero argentino. Historia de lucha de los trabajadores y la CGT. Fabro. Buenos Aires.

Dussel, Inés; Finocchio, Silvia y Gojman, Silvia (1997) Haciendo memoria en el país de nunca más. Editorial Universitaria de Buenos Aires. Buenos Aires.

Estermann, Josef (2014) “Colonialidad, descolonización e interculturalidad”. Revista Polis N 38. Disponible en: http://journals. openedition.org/polis/10164. Consultado el 31/07/2018.

Forte, Ricardo (2017) “Génesis del nacionalismo militar. Participación política y orientación ideológica de las fuerzas armadas argentinas al comienzo del siglo XX”. Revista Signos Históricos, v. 1, n. 2. Disponible en: <http://signoshistoricos.izt.uam.mx/...> . Acceso el 21 de julio de 2018.

Freedman, Lawrence, Gamba-Stonehouse, Virginia (1992). Señales de guerra: el conflicto de las Islas Malvinas 1982. Javier Vergara Editor. Buenos Aires.

Guber, Rosana (2001) Por qué Malvinas?: de la causa nacional a la guerra absurda. Fondo De Cultura Económica. Buenos Aires.

Jaramillo, Jesús (2012) "Nacionalismo territorialista en textos escolares: representaciones de la Patagonia en la dictadura militar argentina (1966-1983)”. Educação e Pesquisa. vol. 38, no 1. Disponible en http://www.scielo.br/pdf/ep/v38n1/a11. Consultado en línea el 31/07/2018.

Laferriere, Guillermo -Soprano, Germán (2010) “Los militares como grupo social y su inscripción en el Estado y la sociedad argentina. Batallas intelectuales y políticas por la construcción de un objeto de estudio en las ciencias sociales”. Revista Digital Universitaria del Colegio Militar de la Nación, vol. 8, no 22.

Leguizamón, Lucía, et al. (2012) "Un estudio exploratorio de los efectos psicosomáticos en ex combatientes de Malvinas y su relación con dimensiones de personalidad.” Revista diálogos vol. 3. $\mathrm{n}^{\circ}$ 1. Disponible en http://www.dialogos.unsl.edu.ar/docs/numeros/5.pdf\#page=46. Consultado en línea el 31/07/2018.

Lorenz, Federico (2006) La Guerra de Malvinas. Edhasa. Buenos Aires.

- (2007) “La necesidad de Malvinas”. Revista Puentes, No 20, Comisión Provincial por la Memoria. La Plata.

Palermo, Vicente (2007) Sal en las heridas. Malvinas en la cultura argentina contemporánea. Sudamericana. Buenos Aires.

Pozzi, Pablo. (1988). Oposición obrera a la dictadura, 1976-1982. Editorial Contrapunto. Buenos Aires.

Pucciarelli, Alfredo (2004) Empresarios, tecnócratas y militares. La trama corporativa de la última dictadura. Siglo XXI. Buenos Aires.

Quiroga, Hugo (2004) El tiempo del Proceso. Homo Sapiens. Buenos Aires.

Rattenbach Benjamín. (1988). Informe Rattenbach: el drama de Malvinas. Espartaco. Buenos Aires.

Reddy, William (2001) The Navigation of Feeling: A Framework for the History of Emotions. Cambridge University Press. Cambridge.

Rodríguez Molas, Ricardo (1983) El servicio militar obligatorio. Centro Editor de América Latina. Buenos Aires.

Rodríguez, Laura (2009) “La Historia que debía enseñarse durante la última dictadura militar en Argentina (1976-1983)”. Antíteses, 2009, vol. 2, no 3. Disponible en: http://www.redalyc.org/html/1933/193317383012/. Consultado en línea el 30/07/2018.

Russell Roberto (1990) El proceso de toma de decisiones en la política exterior argentina 1976-1989. GEL. Buenos Aires.

Schvarzer, Jorge (1986) La política económica de Martínez de Hoz. CISEA-Hyspamerica. Buenos Aires.

Silitti, Nicolás (2018) “El Servicio Militar obligatorio y la 'cuestión social': apuntes para la construcción de un problema historiográfico”. Pasado Abierto, v. 4, n. 7. Disponible en: <https://fh.mdp.edu.ar/revistas/inde...> . Acceso el 21 de julio de 2018.

Simonoff, Alejandro (2017) "Presentación del vigesimosexto informe semestral sobre Política Exterior del gobierno argentino (septiembre 2016-marzo 2017): inserción argentina en los inicios de la era Trump”. Relaciones Internacionales, ${ }^{\circ} 52$. Disponible $^{\circ}$ en: http://sedici.unlp.edu.ar/handle/10915/61606. Consultado en línea el 31/07/2018.

Souto Kustrin, Sandra (2007) "Juventud, teoría e historia: la formación de un sujeto social y de un objeto de análisis". Historia Actual, $\mathrm{N}^{\circ} .13$. Disponible en https://dialnet.unirioja.es/servlet/articulo?codigo=2479343. Consultado el 02/08/2018.

1 Leopoldo Fortunato Galtieri, Discurso del día 2 de abril de 1982, pronunciado desde los balcones de la Casa Rosada hacia la Plaza de Mayo. Ciudad de Buenos Aires, Argentina. Disponible en :http://constitucionweb.blogspot.com/2012/02/discurso-delgral-galtieri-del-2-de.html. Consultado en línea el 29/07/2018. 
2 El movimiento obrero en la última etapa del gobierno civil-militar argentino, estaba dividida en dos grandes centrales: la CGT Brasil y la CGT Azopardo. Al respecto véase Pozzi, Pablo. (1988). Oposición obrera a la dictadura, 1976-1982. Editorial Contrapunto. Díaz, Claudio. (2010). El movimiento obrero argentino. Historia de lucha de los trabajadores y la CGT. Buenos Aires, ediciones Fabro.; Bonnet, Alberto (2014) La izquierda argentina y la guerra de las Malvinas. Razón y Revolución, $\mathrm{n}^{\circ}$ 3. Disponible en http://www.revistaryr.org.ar/index.php/RyR/article/view/456. Consultado en línea el 29/07/2018.

Para un análisis desde múltiples perspectivas, véase Rozitchner, León (1985). Las Malvinas: de la guerra "sucia” a la guerra “limpia”. Centro Editor de América Latina. Buenos Aires; Cardoso, Oscar Raúl, Kirschbaum, Ricardo y van der Kooy, Eduardo (1997) Malvinas: la trama secreta. Planeta. Buenos Aires. Guber, Rosana (2001) Por qué Malvinas?: de la causa nacional a la guerra absurda. Buenos Aires. Fondo De Cultura Económica. Lorenz, Federico (2006) La Guerra de Malvinas. Edhasa. Buenos Aires; Lorenz, Federico (2007) “La necesidad de Malvinas”. Revista Puentes, No 20. Comisión Provincial por la Memoria. La Plata.

Rodríguez, Laura (2009) La Historia que debía enseñarse durante la última dictadura militar en Argentina (1976-1983). Antiteses, vol. 2, no 3. Disponible en: http://www.redalyc.org/html/1933/193317383012/. Consultado en línea el 30/07/2018. Jaramillo, Jesús(2012) Nacionalismo territorialista en textos escolares: representaciones de la Patagonia en la dictadura militar argentina (19661983). Educação e Pesquisa. vol. 38, no 1. Disponible en http://www.scielo.br/pdf/ep/v38n1/a11. Consultado en línea el $31 / 07 / 2018$.

$5 \quad$ Al respecto véase Billig, Michael (2014) Nacionalismo Banal. Capitán Swing. Madrid.

$6 \quad$ La orden de no generar bajas civiles o militares británicas (o malvinenses) era parte de la Operación Rosario. Al respecto véase Freedman, Lawrence, Gamba-Stonehouse, Virginia (1992). Señales de guerra: el conflicto de las Islas Malvinas 1982. Javier Vergara Editor. Buenos Aires.

\section{Palermo, Vicente (2007) Sal en las heridas. Malvinas en la cultura argentina contemporánea. Sudamericana. Buenos Aires.}

Al respecto de la aplicación del Terrorismo de Estado durante la última dictadura civil-militar argentina, véase Dussel, Inés, Finocchio, Silvia y Gojman, Silvia (1997) Haciendo memoria en el país de nunca más. Editorial Universitaria de Buenos Aires. Buenos Aires; Crenzel, Emilio (2008) La historia política del Nunca Más. La memoria de las desapariciones en la Argentina. Siglo XXI. Buenos Aires; Águila, Gabriela (2008) Dictadura, represión y sociedad en Rosario. Un estudio sobre la represión las actitudes y comportamientos sociales en dictadura. Prometeo. Buenos Aires. Para obtener un panorama sobre las modificaciones en la política económica, véase Canitrot, Adolfo (1979) "La disciplina como objetivo de la política económica. Un ensayo sobre el programa económico del gobierno argentino desde 1976” Estudios CEDES, Vol. 2, № 6, Buenos Aires. Canitrot, Adolfo (1982) “Teoría y práctica del liberalismo; política antiinflacionaria y apertura económica en la Argentina, 1976/1981”, en Desarrollo Económico, vol. 21, No 82, Buenos Aires; Schvarzer, Jorge (1986) La política económica de Martinez de Hoz. CISEA-Hyspamerica, Buenos Aires; Kosacoff-. Aspiazu (1989), La industria argentina: desarrollo y cambios estructurales CEPAL-CEAL. Buenos Aires; Pucciarelli, Alfredo (2004) Empresarios, tecnócratas y militares. La trama corporativa de la última dictadura. Siglo XXI. Buenos Aires.

9 Russell Roberto (1990) El proceso de toma de decisiones en la política exterior argentina 1976-1989. Buenos Aires. GEL; Canelo, Paula (2012) “Los efectos del poder tripartito. La balcanización del gabinete nacional durante la última dictadura militar" en Prohistoria, núm. 17, año XV. Finalmente, la referencia a la fuente de Rattenbach Benjamín. (1988). Informe Rattenbach: el drama de Malvinas. Buenos Aires. Espartaco, que deja al descubierto tal situación generando una serie de controversias y repercusiones a la hora de su publicación.

${ }^{10}$ Quiroga, Hugo (2004) El tiempo del Proceso. Homo Sapiens. Buenos Aires. También véase Canelo, Paula (2008). El Proceso en su laberinto: la interna militar de Videla a Bignone. Prometeo Libros Editorial. Buenos Aires.

11 Con relación al concepto de “joven o jóvenes” que utilizaremos en este trabajo, realizamos la aclaración de que no contiene una connotación específica más que la de señalar uno de los rasgos de los protagonistas (su edad). Asimismo, no nos valdremos de concepciones tales como "chicos de la guerra" para describir la situación de los soldados conscriptos argentinos en las Islas Malvinas, pues el film no repite tal imagen creada a posteriori y que genera divisiones en la actualidad dentro del cuerpo de Veteranos de Guerra. Sobre una aproximación al problema de la juventud como categoría analítica, véase Souto Kustrin, Sandra (2007) “Juventud, teoría e historia: la formación de un sujeto social y de un objeto de análisis”. Historia Actual Online, $\mathrm{N}^{\circ}$.13. Disponible en https:// dialnet.unirioja.es/servlet/articulo?codigo=2479343. Consultado el 02/08/2018.

12 Cabe la aclaración de que Juan Soria, nuestro protagonista, estaba prestando servicio en las Fuerzas Armadas. La ley No 4.031, aprobada en al año 1901, estableció la obligatoriedad del servicio militar en Argentina y tuvo vigencia hasta el año 1994. Con relación al concepto "colimba”, el mismo hace referencia a la abreviatura de tres de las principales actividades que debían realizar los conscriptos: correr, limpiar, barrer. Al respecto véase Rodríguez Molas, Ricardo (1983), El servicio militar obligatorio. Centro Editor de América Latina. Buenos Aires; Forte, Ricardo (2017) “Génesis del nacionalismo militar. Participación política y orientación ideológica de las fuerzas armadas argentinas al comienzo del siglo XX”. Signos Históricos, v. 1, n. 2. Disponible en: <http://signoshistoricos.izt.uam.mx/...> . Acceso el 21 de julio de 2018. Laferriere, Guillermo-Soprano, Germán (2010) . "Los militares como grupo social y su inscripción en el Estado y la sociedad argentina. Batallas intelectuales y políticas por la construcción de un objeto de estudio en las ciencias sociales”. Revista Digital Universitaria del Colegio Militar de la Nación, vol. 8, no 22. Silitti, Nicolas (2018) "El Servicio Militar obligatorio y la 'cuestión social': apuntes para la construcción de un problema historiográfico". Pasado Abierto, v. 4, n. 7. Disponible en: <https://fh.mdp.edu.ar/revistas/inde...> . Consultado el 21/07/2018.

13 Una lectura en tal clave puede hallarse en Bourke, Joanna (1999) Sed de sangre. Historia intima del combate cuerpo a cuerpo en las guerras del siglo XX. Critica. Barcelona. 
14 El Comité Especial de Descolonización es un organismo que se originó en el año 1961 con el objetivo de controlar e impulsar procesos de descolonización de aquellos territorios considerados no autónomos. Una interesante perspectiva puede obtenerse en Estermann, Josef (2014) “Colonialidad, descolonización e interculturalidad“. Revista Polis N³8. Disponible en: http://journals. openedition.org/polis/10164. Consultado el 31/07/2018.

15 Fue en diciembre del año 2016 en el que ambos gobiernos, el británico y el argentino, anunciaron el inicio de tareas de reconocimiento de los restos de los caídos enterrados en el Cementerio Darwin. Véase Simonoff, Alejandro (2017). Presentación del vigesimosexto informe semestral sobre Política Exterior del gobierno argentino (septiembre 2016-marzo 2017): inserción argentina en los inicios de la era Trump. Relaciones Internacionales, ${ }^{\circ}$ 52. Disponible en: http://sedici.unlp.edu.ar/handle/10915/61606. Consultado en línea el 31/07/2018.

16 Al respecto véase Leguizamón, Lucía, et al. (2012) "Un estudio exploratorio de los efectos psicosomáticos en ex combatientes de Malvinas y su relación con dimensiones de personalidad.” Revista diálogos vol. 3. $\mathrm{n}^{\circ}$ 1. Disponible en http://www.dialogos.unsl. edu.ar/docs/numeros/5.pdf\#page=46. Consultado en línea el 31/07/2018.

17 A pesar de no contar con cifras oficiales, desde diferentes asociaciones de Veteranos sostienen que tras la Guerra de Malvinas, el número de suicidios superó a la cantidad de caídos en combate. Una postura al respecto nos ofrece el Presidente de la Asociación Veteranos Defensores de Malvinas, Víctor Ibáñez. Al respecto véase: https://elpodiomendoza.com/53701-confesiones-victor-ibanez/. Consultado en línea el 31/07/2018.

18 En este sentido, resulta interesante la propuesta de William Reddy, quien postula la existencia de "regímenes emocionales”, que determinan en cada espacio social, la forma en la que los sujetos deben manifestar sus emociones. Por tanto, el individuo, en este caso Juan, busca evadir de diferentes formas aquellas imposiciones y manifestar en diferentes "refugios", tales como el arte y la sustracción del resto del mundo, sus propias emociones. Al respecto véase Reddy, William (2001) The Navigation of Feeling: A Framework for the History of Emotions. Cambridge University Press. Cambridge.

19 Se toma el concepto de comunidad imaginada de la obra de Anderson, Benedict (1993) Comunidades Imaginadas: Reflexiones sobre el origen y la difusión del nacionalismo.

20 Acerca de la identidad de los ex combatientes reconocidos, véase https://www.infobae.com/sociedad/2018/03/26/ uno-por-uno-quienes-fueron-los-soldados-argentinos-identificados-en-el-cementerio-de-malvinas/. Consultado el 02/08/2018. 